\section{Pacific Northwest}

National Laboratory

Operated by Battelle for the

U.S. Department of Energy

\title{
Sonochemical Digestion of High-Fired Plutonium Dioxide Samples
}

\author{
S. I. Sinkov \\ G. J. Lumetta
}

October 2006

Prepared for the U.S. Department of Energy under Contract DE-AC05-76RL01830 


\title{
DISCLAIMER
}

This report was prepared as an account of work sponsored by an agency of the United States Government. Neither the United States Government nor any agency thereof, nor Battelle Memorial Institute, nor any of their employees, makes any warranty, express or implied, or assumes any legal liability or responsibility for the accuracy, completeness, or usefulness of any information, apparatus, product, or process disclosed, or represents that its use would not infringe privately owned rights. Reference herein to any specific commercial product, process, or service by trade name, trademark, manufacturer, or otherwise does not necessarily constitute or imply its endorsement, recommendation, or favoring by the United States Government or any agency thereof, or Battelle Memorial Institute. The views and opinions of authors expressed herein do not necessarily state or reflect those of the United States Government or any agency thereof.

\author{
PACIFIC NORTHWEST NATIONAL LABORATORY \\ operated by \\ BATTELLE \\ for the \\ UNITED STATES DEPARTMENT OF ENERGY \\ under Contract DE-ACO5-76RL01830
}

Printed in the United States of America
Available to DOE and DOE contractors from the
Office of Scientific and Technical Information,
P.O. Box 62, Oak Ridge, TN 37831-0062;
ph: (865) 576-8401
fax: (865) 5765728
email: reports@adonis.osti.gov

\footnotetext{
Available to the public from the National Technical Information Service, U.S. Department of Commerce, 5285 Port Royal Rd., Springfield, VA 22161 ph: (800) 553-6847 fax: (703) 605-6900

email: orders@nits.fedworld.gov online ordering: http://www.ntis.gov/ordering.htm
} 


\title{
Sonochemical Digestion of High-Fired Plutonium Dioxide Samples
}

\author{
S. I. Sinkov \\ G. J. Lumetta
}

October 2006

Prepared for the U.S. Department of Energy

under Contract DE-AC05-76RL01830

Pacific Northwest National Laboratory

Richland, Washington 99352 


\section{Summary}

This work was performed as part of a broader effort to automate analytical methods for determining plutonium and other radioisotopes in environmental samples. The work described here represented a screening study to evaluate the effect of applying ultrasonic irradiation to dissolve high-fired plutonium oxide. The major findings of this work can be summarized as follows:

- High-fired $\mathrm{PuO}_{2}$ does not undergo measurable dissolution when sonicated in nitric acid solutions, even at a high concentration range of $\mathrm{HNO}_{3}$ where the calculated thermodynamic solubility of $\mathrm{PuO}_{2}$ exceeds the $\mu \mathrm{g} / \mathrm{mL}$ level.

- Applying organic complexants (nitrilotriacetic acid) and reductants (hydroxyurea) in $1.5 \mathrm{M} \mathrm{HNO}_{3}$ does not significantly increase the dissolution compared with digestion in nitric acid alone. Nearly all (99.5\%) of the $\mathrm{PuO}_{2}$ remains undissolved under these conditions.

- The action of a strong inorganic reductant, $\mathrm{TiCl}_{3}$ in $25 \mathrm{wt} \% \mathrm{HCl}$, results in $40 \%$ dissolution of the $\mathrm{PuO}_{2}$ when the $\mathrm{TiCl}_{3}$ concentration is $\geq 1 \mathrm{wt} \%$ under sonication.

- Oxidative treatment of $\mathrm{PuO}_{2}$ by freshly dissolved $\mathrm{AgO}(\sim 20 \mathrm{mg} / \mathrm{mL})$ in $1.5 \mathrm{M} \mathrm{HNO}_{3}$ with sonication resulted in $95 \% \mathrm{PuO}_{2}$ dissolution. However, the same treatment of $\mathrm{PuO}_{2}$ mechanically mixed with $50 \mathrm{mg}$ of Columbia River sediment (CRS) results in a significant decrease of dissolution yield of $\mathrm{PuO}_{2}(<20 \%$ dissolved at the same $\mathrm{AgO}$ loading $)$ because of parasitic consumption of $\mathrm{Ag}^{2+}$ by oxidizable components of the CRS.

- Digesting $\mathrm{PuO}_{2}$ in $\mathrm{HF}$ resulted in dissolution yields slightly higher than $80 \%$ for HF concentration from $6 \mathrm{M}$ to $14 \mathrm{M}$. Sonication did not result in any improvement in dissolution efficiency in HF.

- Mixed nitric acid/HF solutions result in a higher dissolution yield of $\mathrm{PuO}_{2}$ compared with digestion in $\mathrm{HF}$ alone (at the same HF concentrations). Practically quantitative dissolution of $\mathrm{PuO}_{2}$ can be achieved with 6 to $8 \mathrm{M} \mathrm{HNO}_{3}+14 \mathrm{M} \mathrm{HF}$ or $8 \mathrm{M} \mathrm{HNO}_{3}+4 \mathrm{M} \mathrm{HF}$ mixtures. In the latter case, quantitative dissolution of $\mathrm{PuO}_{2}$ was demonstrated only with sonication.

Overall, the results indicate that applying ultrasound in an isolated cup horn configuration to dissolve refractory $\mathrm{PuO}_{2}$ does not offer any substantial advantage over conventional "heat and mix" treatment. Oxidative treatment by $\mathrm{AgO}$ appears to be effective only when very little or no oxidizable materials are present in the digested sample. The catalytic use of $\mathrm{Ag}^{2+}$ in the "Catalyzed Electrolytic Plutonium Oxide Dissolution" technology would probably be more effective than using $\mathrm{AgO}$ because the $\mathrm{Ag}^{2+}$ is continually regenerated electrochemically. Reductive treatment with $\mathrm{TiCl}_{3}$ in $\mathrm{HCl}$ solution proves to be less efficient than the previously observed effect based on in situ generation of $\mathrm{Ti}^{3+}$ in $\mathrm{H}_{3} \mathrm{PO}_{4}$ and $\mathrm{H}_{2} \mathrm{SO}_{4}$ media using a dip probe sonication setup. The previous experiments, however, were performed at higher temperature and with non-steady concentration profiles of $\mathrm{Ti}^{3+}$ in the process of sonochemical digestion. 



\section{Acronyms}

CEPOD Catalyzed Electrolytic Plutonium Oxide Dissolution

CRS

Columbia River Sediment

DI

deionized (water)

HF

hydrofluoric acid

$\mathrm{HNO}_{3}$

nitric acid

HU

hydroxyurea (HO-NH-C(O)- $\mathrm{NH}_{2}$ )

LSC

liquid scintillation counting

NIST

National Institute of Standards and Technology

NOM

natural organic matter

NTA

nitrilotriacetic acid $\left[\mathrm{N}-\left(\mathrm{CH}_{2}-\mathrm{COOH}\right)_{3}\right]$

SRM

standard reference material 



\section{Acknowledgments}

This work was funded by the National Nuclear Security Agency (NA-22). Pacific Northwest National Laboratory is operated by Battelle for the U.S. Department of Energy under Contract

DE-AC05-76RL01830. The authors thank Wayne Cosby and Brian Rapko for their review of this manuscript. 



\section{Contents}

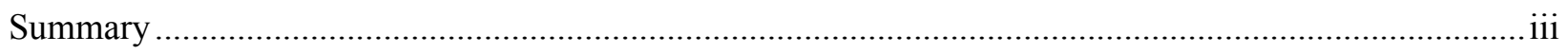

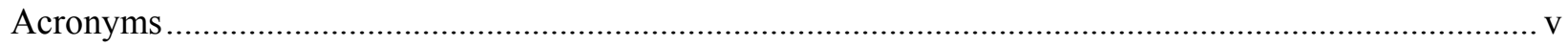

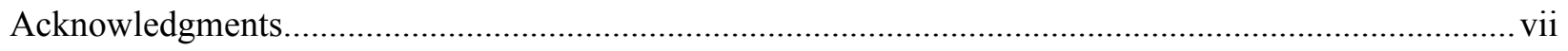

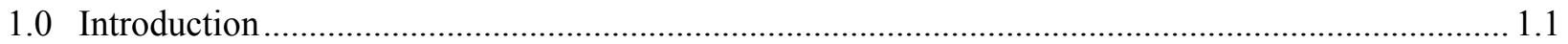

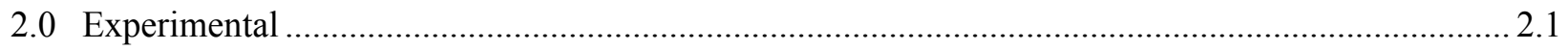

2.1 $\mathrm{PuO}_{2}$ Preparation and Subsampling for Dissolution Experiments ......................................... 2.1

2.2 Calculation of Specific Alpha Activity of ${ }^{239,240} \mathrm{Pu}$............................................................. 2.1

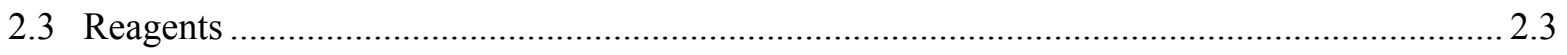

2.4 Digested Sample Pretreatment and Filtration..................................................................... 2.3

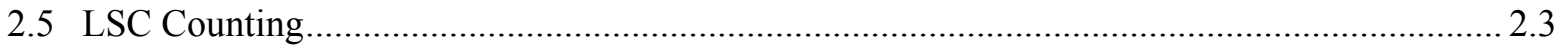

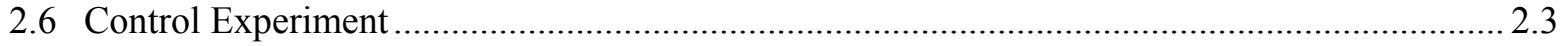

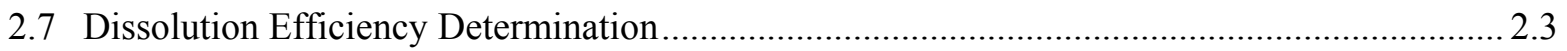

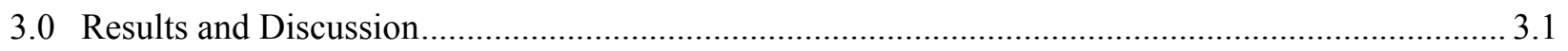

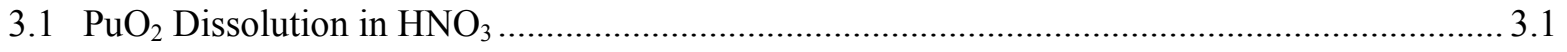

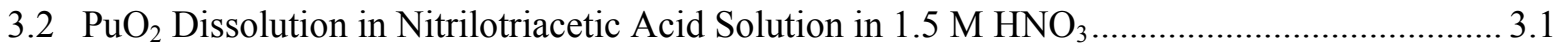

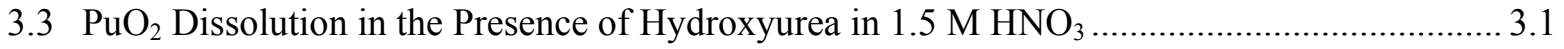

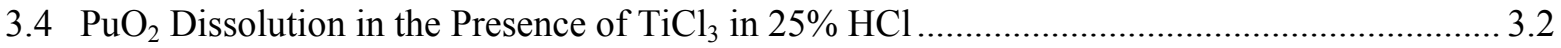

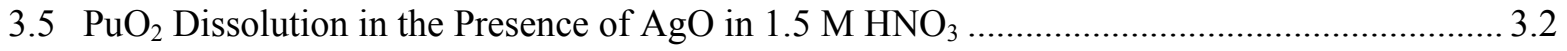

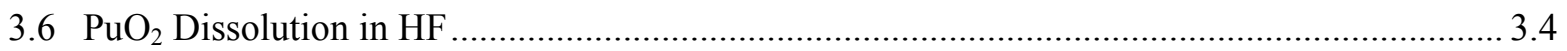

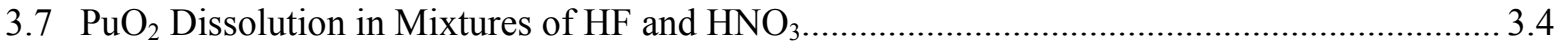

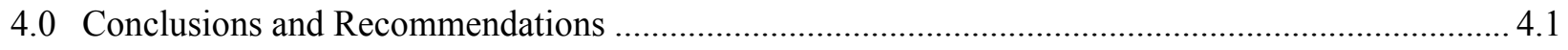

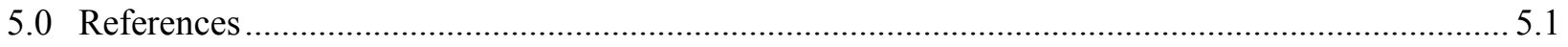




\section{Figures}

2.1. a, left) Sonication Apparatus in a Cup Horn Configuration Used in this Project; b, right) SelfCentering Vial Holder.

2.2. Temperature Profile Measured Inside of a Cup Horn Water Bath During 60 min of Sonication Run at $46 \%$ of Full Power (dial setting at $40 \%$ of full scale)

3.1. Dissolution Efficiency of $\mathrm{PuO}_{2}$ in Hydrochloric Solution of $\mathrm{TiCl}_{3}$

3.2. Dissolution Efficiency of $\mathrm{PuO}_{2}$ in $1.4 \mathrm{M} \mathrm{HNO}_{3}$ in the Presence of $\mathrm{AgO}$

3.3. Dissolution Efficiency of $\mathrm{PuO}_{2}$ Premixed with CRS $\left(29 \mu \mathrm{g}\right.$ of $\mathrm{PuO}_{2}$ per $50 \pm 1 \mathrm{mg}$ of the $\mathrm{CRS}$ ) in $1.4 \mathrm{M} \mathrm{HNO}_{3}$ in the Presence of $\mathrm{AgO}$

3.4. Dissolution Efficiency of $\mathrm{PuO}_{2}$ in Hydrofluoric Acid

3.5. Dissolution Efficiency of $\mathrm{PuO}_{2}$ in $\mathrm{HF}$ Solution in $8 \mathrm{M} \mathrm{HNO}_{3}$

3.6. Dissolution Efficiency of $\mathrm{PuO}_{2}$ in $\mathrm{HNO}_{3}$ Solution in $14 \mathrm{M} \mathrm{HF}$ 


\subsection{Introduction}

The application of ultrasound in chemistry (i.e., sonochemistry) has evolved over the last two decades. Introducing ultrasonic waves into a liquid such as water creates microbubbles that collapse implosively, forming localized "hot spots." This phenomenon is generally referred to as cavitation. The interesting feature of the cavitation effect is that the temperatures in the hot spots are roughly $5000^{\circ} \mathrm{C}$ with pressures of several hundred atmospheres, but the bulk solution conditions remain at near ambient conditions (Suslick 1988). The extreme localized temperature and pressure conditions caused by acoustic cavitation can open up reaction pathways that are not easily accessible otherwise.

In our previous study on the enhancement of $\mathrm{Pu}(\mathrm{IV})$ colloids and dioxide dissolution by sonochemistry ${ }^{(a)}$ using a dip horn configuration of the sonicating probe, we observed, among other things, that:

- Sonication was found to significantly increase the dissolution of low-fired $\mathrm{PuO}_{2}$ in $2.5 \mathrm{M} \mathrm{H}_{3} \mathrm{PO}_{4}$ or $2.5 \mathrm{M} \mathrm{H}_{2} \mathrm{SO}_{4}$. Sonication increased the rate of dissolution by $\sim 300$-fold. High-fired $\mathrm{PuO}_{2}$ was also investigated and found to be more resistant to dissolution with better leaching efficiency obtained in sulfuric acid solution.

- The appearance of purple color in these systems suggests the formation of $\mathrm{Ti}^{3+}$ because of minor corrosion of the ultrasonic probe. The role (if any) $\mathrm{fi}^{3+}$ in the oxide dissolution was not determined in the prior work.

In those experiments, a titanium sonicating horn was directly immersed into solution. A significant enhancement in dissolution efficiency of low-fired $\mathrm{PuO}_{2}$ was observed in phosphoric and sulfuric media only, and it was accompanied by the progressive appearance of the purple color characteristic of $\mathrm{Ti}^{3+}$ during sonication. No coloration was observed in the nitric acid solution, and no significant dissolution of $\mathrm{PuO}_{2}$ under sonication was observed in $\mathrm{HNO}_{3}(<0.5 \%$ of total dissolved alpha activity in solution). At that stage, it was concluded that future studies should explore the impact of changes to the sonochemical equipment with particular emphasis on systems in which the probe is not directly inserted into the reaction medium; this would avoid corrosion of the probe and cross-contamination of the solutions. It was also suggested that control experiments should be conducted on the dissolution of $\mathrm{PuO}_{2}$ in $\mathrm{H}_{3} \mathrm{PO}_{4}$ and $\mathrm{H}_{2} \mathrm{SO}_{4}$ solutions in which $\mathrm{Ti}^{3+}$ is added to determine the extent to which $\mathrm{Ti}^{3+}$ participates in the dissolution mechanism.

The aim of the current project has been to further explore the potential advantages of sonication in enhanced dissolution of refractory $\mathrm{PuO}_{2}$ in acidic media to determine the role of various complexing, reducing, and oxidizing agents using a modified sonicating instrument based on a cup horn sonication geometry as opposed to the previously tested dip probe configuration.

(a) GJ Lumetta, SI Sinkov, and JI Friese. 2005. Enhancing Actinide Separations by Sonochemistry (FY 2005 Report, Unpublished Manuscript). 


\subsection{Experimental}

The sonication apparatus consisted of a 2-inch-wide cup horn coupled to a Model CL4 converter (20 kHz), which was driven by a Model XL-2010 power supply (all equipment was obtained from Misonix, Inc.; formerly Heat Systems, Farmingdale, New York). The use of the cup horn configuration avoids contact of the sample with metallic components (as would be the case for a dip horn) that might interfere with subsequent analytical procedures. Figure 2.1 illustrates the experimental apparatus. The sonicator was operated at a starting power output of $46 \%$ (power dial setting 4.0 in the scale of 1 to 10 ). No means were taken to maintain constant temperature during the experiments, but under the conditions used (0.5- to 0.75 -inch-thick water layer above a top surface of the sonicating horn), the temperature typically reached $80^{\circ} \mathrm{C}$ within the first 40 minutes of sonication with an additional rise to $84^{\circ} \mathrm{C}$ over the next 20 min. Figure 2.2 shows the detailed temperature profile in the sonication sample compartment. Control experiments were performed using a heated water bath with a capacity for five vials with a heating mode resembling the sonication temperature profile. Occasional mechanical stirring was applied to agitate the control samples during digestion. Glass and plastic vials of 4-mL capacity were used for digestion experiments in HF free media and in the presence of HF, respectively. Contact times of $1 \mathrm{hr}$ were employed in all sonication and control experiments.

\section{1 $\mathrm{PuO}_{2}$ Preparation and Subsampling for Dissolution Experiments}

High-fired $\mathrm{PuO}_{2}$ was prepared by calcination of a small amount of low-fired $\mathrm{PuO}_{2}$ in a muffle furnace at $1000^{\circ} \mathrm{C}$ for $4 \mathrm{hrs}$. Several nominally $1-\mathrm{mg}$ portions of the calcination product were weighed out using a five-place balance (LE 222D, Sartorius) setup in a glovebox. Their weight was determined with a 10- $\mu \mathrm{g}$ uncertainty. The pre-weighed portion of $\mathrm{PuO}_{2}$ was transferred into a fume hood where it was mixed with deionized (DI) water (in a $1.00 \mathrm{mg} \mathrm{PuO}_{2}$ to $1.50 \mathrm{~mL} \mathrm{H}_{2} \mathrm{O}$ ratio) to prepare aqueous suspensions of this material suitable for safe handling in a fume hood. Portions of $\mathrm{PuO}_{2}(\sim 33 \mu \mathrm{g}$ of the material) used in the digestion experiments were produced by pipetting $50-\mu \mathrm{L}$ aliquots out of the stock suspension vial. The transfer was carried out under constant magnetic stirring $(400 \mathrm{rpm})$ of the suspension to eliminate concentration gradients within the volume of the stock solution, which otherwise would develop without agitation because of quick sedimentation of the high-density powder of $\mathrm{PuO}_{2}$ in water.

\subsection{Calculation of Specific Alpha Activity of ${ }^{239,}{ }^{240} \mathrm{Pu}$}

The $\mathrm{PuO}_{2}$ used in this project represented a mixture of ${ }^{239} \mathrm{Pu}(93.85 \%),{ }^{240} \mathrm{Pu}(5.98 \%)$, and ${ }^{241} \mathrm{Pu}$ $(0.22 \%)$ with traces of ${ }^{238} \mathrm{Pu}$ and ${ }^{242} \mathrm{Pu}$. Plutonium-241 is a beta-emitter with a relatively short half life of 14.4 years. It does not contribute directly to the total alpha-activity from other Pu isotopes in this mixture, but its decay product, ${ }^{241} \mathrm{Am}$, does. Because no information was available on the date of the last purification of this $\mathrm{Pu}$ sample from ${ }^{241} \mathrm{Am}$, an assumption was made that $50 \%$ out of the initial $0.22 \%$ of

${ }^{241} \mathrm{Pu}$ had decayed into the daughter product. This assumption corresponds to one half life of ${ }^{241} \mathrm{Pu}$ or 14.4 years since the last purification from ${ }^{241} \mathrm{Am}$. Two other extreme cases (complete absence of ${ }^{241} \mathrm{Am}$ and $100 \%$ conversion of ${ }^{241} \mathrm{Pu}$ into ${ }^{241} \mathrm{Am}$ ) would change the total specific activity of this mixture of $\mathrm{Pu}$ isotopes by $\pm 4.6 \%$. The calculated specific activity of this particular Pu sample is $2.87 \times 10^{6} \mathrm{~Bq} / \mathrm{mg}$ of Pu (as Pu metal). This value is $25 \%$ higher than the one based on the frequently used simplified assumption that all specific activity in the weapons-grade plutonium can be attributed solely to ${ }^{239} \mathrm{Pu}$. 


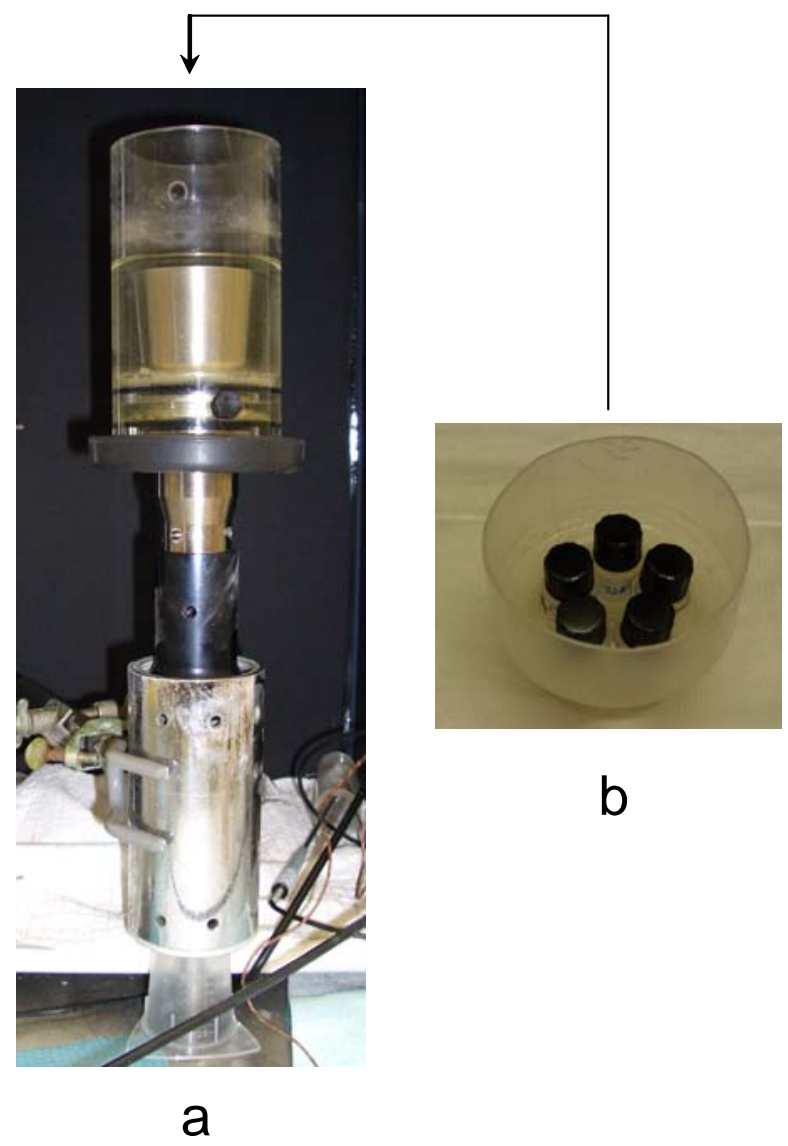

Figure 2.1. a, left) Sonication Apparatus in a Cup Horn Configuration Used in this Project; b, right) Self-Centering Vial Holder

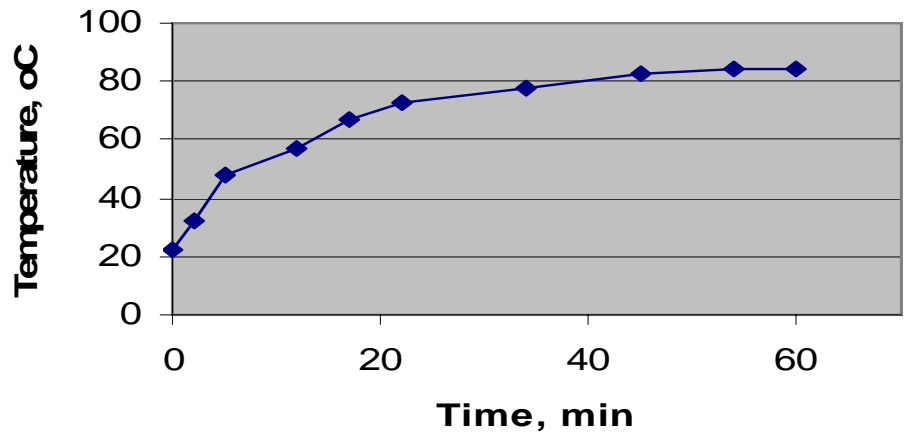

Figure 2.2. Temperature Profile Measured Inside of a Cup Horn Water Bath During 60 min of Sonication Run at $46 \%$ of Full Power (dial setting at $40 \%$ of full scale) 


\subsection{Reagents}

All solutions were prepared using DI water as a solvent. Nitric acid and $\mathrm{HCl}$ were of trace metal grade purity. Titanium trichloride solutions (in the $\mathrm{Ti}^{3+}$ concentration range of 0.5 to $2 \mathrm{wt} \%$ ) were prepared by diluting a $10 \mathrm{wt} \% \mathrm{TiCl}_{3}$ stock solution in 20 to $30 \mathrm{wt} \% \mathrm{HCl}$ (Sigma-Aldrich) with a $25 \mathrm{wt} \%$ $\mathrm{HCl}$ solution. Hydroxyurea (98\% purity), $\mathrm{AgO}$, and nitrilotriacetic acid (99\%) were obtained from Aldrich Chemical Company.

\subsection{Digested Sample Pretreatment and Filtration}

A syringe filtration technique was employed to separate unreacted $\mathrm{PuO}_{2}$ from the dissolved plutonium before determining the amount of dissolved plutonium by liquid scintillation counting (LSC). A $0.20-\mu \mathrm{m}$ Nylon membrane filter was used for this purpose. If the acidic sample contained $\mathrm{HNO}_{3}$ or $\mathrm{HCl}$ at a concentration of $3 \mathrm{M}$ or higher, the original post-digested sample was diluted with DI water to reduce acidity to $2 \mathrm{M}$ to protect the membrane filter material from destruction in the strongly acidic medium.

\subsection{LSC Counting}

A Tricarb liquid scintillation analyzer (Model 2500 TR) was used to measure the total alpha activity $\left({ }^{239} \mathrm{Pu}+{ }^{240} \mathrm{Pu}+{ }^{241} \mathrm{Am}\right)$ in leachates by spiking an appropriate liquid sample aliquot into $4.0 \mathrm{~mL}$ of Ultima Gold XR liquid scintillation cocktail (Packard Instruments).

\subsection{Control Experiment}

In those cases where sonication showed a significant degree of $\mathrm{PuO}_{2}$ dissolution, control experiments were performed with conventional heat and mix equipment following approximately the same temperature profile as the one observed during the sonication experiments (see Figure 2.2).

\subsection{Dissolution Efficiency Determination}

The total activity of the dissolved $\mathrm{Pu}$ in the digested sample was determined by multiplying the value of the observed activity in the LSC sample by the dilution factor and by the sub-sampling factor (that is, the ratio of the total volume of liquid in the digested sample [typically $1 \mathrm{~mL}$ ] to the volume of this solution taken for analysis). The determined value of the total activity was then compared with the calculated activity of ${ }^{239,240} \mathrm{Pu}$ expected to be present in solution in case of complete dissolution of the $\mathrm{PuO}_{2}$. 


\subsection{Results and Discussion}

This section discusses the dissolution of high-fired $\mathrm{PuO}_{2}$ in $\mathrm{HNO}_{3}$ solutions of various acidity: 1) a solution of nitrilotriacetic acid (NTA) in $1.5 \mathrm{M} \mathrm{HNO}_{3}$ (representing a strong organic complexant favoring the tetravalent state of $\mathrm{Pu}$ in acidic solution), 2) a solution of hydroxyurea (HU) in $1.5 \mathrm{M} \mathrm{HNO}_{3}$ (representing an organic reductant favoring a +3 oxidation state of $\mathrm{Pu}$ in solution), 3 ) a solution of $\mathrm{TiCl}_{3}$ in $\mathrm{HCl}$ (representing a strong inorganic reductant favoring $\mathrm{Pu}(\mathrm{III})$ in solution), 4) a $1.5 \mathrm{M} \mathrm{HNO}_{3}$ solution in the presence of $\mathrm{AgO}$ (representing a strong inorganic oxidant favoring $\mathrm{Pu}(\mathrm{VI})$ in solution), and 5) mixtures of $\mathrm{HF}$ and $\mathrm{HNO}_{3}$ (using fluoride as a powerful inorganic complexing and dissolving agent for $\mathrm{Pu}(\mathrm{IV})$ compounds). Contact times of $1 \mathrm{hr}$ were employed in all sonication and control experiments described in this section.

\section{1 $\mathrm{PuO}_{2}$ Dissolution in $\mathrm{HNO}_{3}$}

Two sets of sonication experiments were performed in $\mathrm{HNO}_{3}$ solutions of variable concentration. In the first set, five samples with $\mathrm{HNO}_{3}$ concentration from 2.0 to $8.3 \mathrm{M}$ were digested, and in the second set, five more samples were processed in the 9.0 to $15.8 \mathrm{M}$ concentration range of $\mathrm{HNO}_{3}$. No appreciable dissolution was observed for any of the 10 concentrations tested. The best result of $0.57 \%$ total dissolved alpha activity was achieved for the $9.0 \mathrm{M} \mathrm{HNO}_{3}$ solution. The average dissolved fraction for all 10 samples was found to be $0.19 \pm 0.16 \%$. No control experiments were performed in this case because no significant dissolution was achieved with sonication.

\section{2 $\mathrm{PuO}_{2}$ Dissolution in Nitrilotriacetic Acid Solution in $1.5 \mathrm{M} \mathrm{HNO}_{3}$}

Solutions of NTA in $1.5 \mathrm{M} \mathrm{HNO}_{3}$ with NTA concentrations ranging from $5 \mathrm{mM}$ to $25 \mathrm{mM}$ were tested for dissolving $\mathrm{PuO}_{2}$ under sonication. NTA is a powerful complexing agent for tetravalent actinides (Sinkov and Lumetta 2006), and it was expected that it may exhibit a good leaching capability for $\mathrm{PuO}_{2}$. In reality, the maximum dissolved fraction of $\mathrm{PuO}_{2}$ observed in our experiments was less then $0.6 \%$, which was obtained with $20 \mathrm{mM}$ NTA; the average value was $0.27 \pm 0.18 \%$ for all five samples tested with this reagent. So NTA/HNO 3 does not appear a promising medium for dissolving high-fired $\mathrm{PuO}_{2}$.

\section{3 $\mathrm{PuO}_{2}$ Dissolution in the Presence of Hydroxyurea in $1.5 \mathrm{M} \mathrm{HNO}_{3}$}

It has been reported recently that $\mathrm{HU}$ can be used as a novel salt-free reductant in nitric acid solutions for conversion of $\mathrm{Pu}(\mathrm{IV})$ to $\mathrm{Pu}$ (III) (Zhaowu et al. 2004). It exhibits superior kinetics over hydroxylamine and its organic derivatives. We tested this reagent in $1.5 \mathrm{M} \mathrm{HNO}_{3}$ solution for reductive leaching of $\mathrm{PuO}_{2}$ with $\mathrm{HU}$ concentrations in the range 40 to $200 \mathrm{mM}$. No significant dissolution was observed with this reagent with or without sonication. The best result was achieved for an HU concentration of $80 \mathrm{mM}$ $(1.0 \mathrm{wt} \%)$, while the average efficiency for the entire series was found to be $0.33 \pm 0.40 \%$. 


\section{4 $\mathrm{PuO}_{2}$ Dissolution in the Presence of $\mathrm{TiCl}_{3}$ in $25 \% \mathrm{HCl}$}

In our previous report, Enhancing Actinide Separations by Sonochemistry, ${ }^{(a)}$ we achieved practically quantitative dissolution of low-fired $\mathrm{PuO}_{2}$ in $2.5 \mathrm{M} \mathrm{H}_{2} \mathrm{SO}_{4}$ and $2.5 \mathrm{M} \mathrm{H}_{3} \mathrm{PO}_{4}$ using an emersion probe sonication geometry. The dissolution process was accompanied by the progressive appearance of purple color, which was attributed to minor corrosion of the sonicating probe in the indicated acids with the formation of $\mathrm{Ti}^{3+}$ in the solution. Titanium(III) is a powerful reducing agent with a formal electrochemical potential of the Ti(IV)/Ti(III) couple in acidic medium close to $0 \mathrm{~V}$. We hypothesized that the presence of $\mathrm{Ti}^{3+}$ in this system may, at least in part, be responsible for the enhanced dissolution of $\mathrm{PuO}_{2}$. In the presence of $\mathrm{Ti}^{3+}, \mathrm{PuO}_{2}$ dissolution might be facilitated by reducing $\mathrm{Pu}(\mathrm{IV})$ on the surface of $\mathrm{PuO}_{2}$ to trivalent $\mathrm{Pu}$ [the similar effect is known for enhanced dissolution of $\mathrm{Fe}_{2} \mathrm{O}_{3}$ in the presence of ascorbic acid, which reduces Fe(III) to Fe(II) (Banwart et al. 1989)].

In this project, we tested the addition of $\mathrm{Ti}^{3+}$ solution to the sonicated samples of high-fired $\mathrm{PuO}_{2}$. The $\mathrm{TiCl}_{3}$ stock solution available for use in these experiments was $10 \% \mathrm{TiCl}_{3}$ in 20 to $30 \% \mathrm{HCl}^{\text {. For this }}$ reason, we decided to perform the digestion in $\mathrm{HCl}$ rather than in the $\mathrm{H}_{2} \mathrm{SO}_{4}$ or $\mathrm{H}_{3} \mathrm{PO}_{4}$ media. The results of this reductive dissolution series are shown in Figure 3.1. The dissolution efficiency achieved for these conditions did not exceed $40 \%$, which is 2.5 times lower than the previously reported values in $\mathrm{H}_{2} \mathrm{SO}_{4}$ and $\mathrm{H}_{3} \mathrm{PO}_{4}$ solutions in which $\mathrm{Ti}^{3+}$ generated in situ led to complete dissolution after $60 \mathrm{~min}$ of sonication. The lower efficiency of $\mathrm{PuO}_{2}$ dissolution in this project might be associated with the lower temperature of digestion $\left(84^{\circ} \mathrm{C}\right.$ after 60 min of digestion vs. $\sim 100^{\circ} \mathrm{C}$ after 5 to $10 \mathrm{~min}$ of sonication in experiments with a dip probe setup). Or, it could simply reflect the greater difficulty in dissolving high-fired $\mathrm{PuO}_{2}$. No control series was performed with the addition of $\mathrm{TiCl}_{3}$ because of an insufficiently high dissolution yield observed in the sonication run.

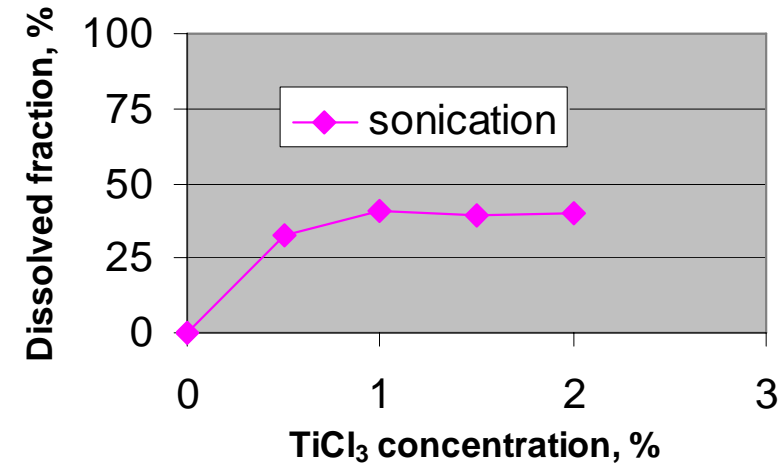

Figure 3.1. Dissolution Efficiency of $\mathrm{PuO}_{2}$ in Hydrochloric Solution of $\mathrm{TiCl}_{3} . \mathrm{C}_{\mathrm{HCl}}=25 \%$.

\section{5 $\mathrm{PuO}_{2}$ Dissolution in the Presence of AgO in $1.5 \mathrm{M} \mathrm{HNO}_{3}$}

The Catalyzed Electrolytic Plutonium Oxide Dissolution (CEPOD) process was developed by Ryan and Bray 3 decades ago (Ryan and Bray 1980; Ryan et al. 1992) and was successfully tested for dissolution of refractory $\mathrm{PuO}_{2}$. The process is based on the oxidative action of the $\mathrm{Ag}^{2+} / \mathrm{Ag}^{+}$ electrochemical couple $\left(\mathrm{E}^{0}=1.98 \mathrm{~V}\right)$. Silver(I) ions carry electrons from a solid $\mathrm{PuO}_{2}$ surface to the anode of the electrochemical cell where the regeneration of $\mathrm{Ag}^{2+}$ takes place. Among other oxidizing metal species potentially suitable for oxidative dissolution of $\mathrm{PuO}_{2}$, including $\mathrm{Ce}^{4+}$ and $\mathrm{Co}^{3+}, \mathrm{the}_{\mathrm{Ag}^{2+}} / \mathrm{Ag}^{+}$ couple has by far the highest rate of electron exchange (about 10,000 times higher than those of Co and Ce), which makes it especially suitable for the CEPOD technology. In this project, we had no access to the CEPOD type of electrochemical cell that would fit inside of a sonicating cup horn cavity.

(a) GJ Lumetta, SI Sinkov, and JI Friese. 2005. Enhancing Actinide Separations by Sonochemistry (FY 2005 Report, Unpublished Manuscript). 
Nevertheless, we decided to test the sonochemical digestion of $\mathrm{PuO}_{2}$ in the presence of $\mathrm{Ag}^{2+}$ ions introduced into the tested solution by dissolving $\mathrm{AgO}$ in nitric acid immediately before performing the digestion. The experiment was performed at a constant acidity of $1.4 \mathrm{M} \mathrm{HNO}_{3}$ with increasing amounts of $\mathrm{AgO}$ powder. The results shown in Figure 3.2 indicate that about $85 \%$ of $\mathrm{PuO}_{2}$ can be dissolved with an initial $\mathrm{AgO}$ concentration of $6 \mathrm{mg} / \mathrm{mL}$ under sonication. On the other hand, only $58 \%$ of the $\mathrm{PuO}_{2}$ dissolved under these conditions in the control experiment in the absence of ultrasound. However, for higher loadings of $\mathrm{AgO}$, the effect of ultrasonic treatment becomes less significant. For example, only a $15 \%$ improvement in the dissolution efficiency is achieved by sonication when the initial $\mathrm{AgO}$ concentration is $20 \mathrm{mg} / \mathrm{mL}$. Incomplete dissolution of $\mathrm{PuO}_{2}$ by this treatment might be related to the limited lifetime of $\mathrm{Ag}^{2+}$ in the solution because of its reduction by water with the release of oxygen $\left(4 \mathrm{Ag}^{2+}+2 \mathrm{H}_{2} \mathrm{O}=\mathrm{O}_{2}+4 \mathrm{H}^{+}+4 \mathrm{Ag}^{+}\right)$. Application of the CEPOD technology with $\mathrm{Ag}^{2+}$ regeneration is expected to improve the dissolution capability of $\mathrm{PuO}_{2}$ in nitric acid at much lower concentrations of silver ions in the dissolving medium.

One more set of experiments on $\mathrm{PuO}_{2}$ dissolution using $\mathrm{AgO}$ was performed at the same acidity but in the presence of significant amounts of Columbia River Sediment (CRS) available from the National Institute of Standards and Technology (NIST) as the Standard Reference Material (SRM) \#4350B (NIST 1981). The purpose of this experiment was to determine to what extent natural organic matter (NOM) and other reducing species present in the CRS decreases the effectiveness of AgO in promoting $\mathrm{PuO}_{2}$ dissolution. As Figure 3.3 shows, the effect of natural reducing components is very significant. It illustrates that even with twice the initial concentration of $\mathrm{AgO}$ in the solution than the highest loading used in the previous experiment, no more than $40 \%$ of $\mathrm{PuO}_{2}$ can be dissolved by this treatment. The data are too scattered to allow any meaningful judgment about the benefits of sonication in this series of experiments. No information was available on the percentage of NOM in the SRM sample tested, so it was not possible to estimate whether the amount of $\mathrm{Ag}^{2+}$ was sufficient to dissolve all the NOM and $\mathrm{Pu}$ in these tests. We believe that much better results on $\mathrm{PuO}_{2}$ dissolution in natural samples with significant amounts of NOM and other reductants can be achieved using the CEPOD-based treatment in which $\mathrm{Ag}^{2+}$ is electrochemically regenerated.

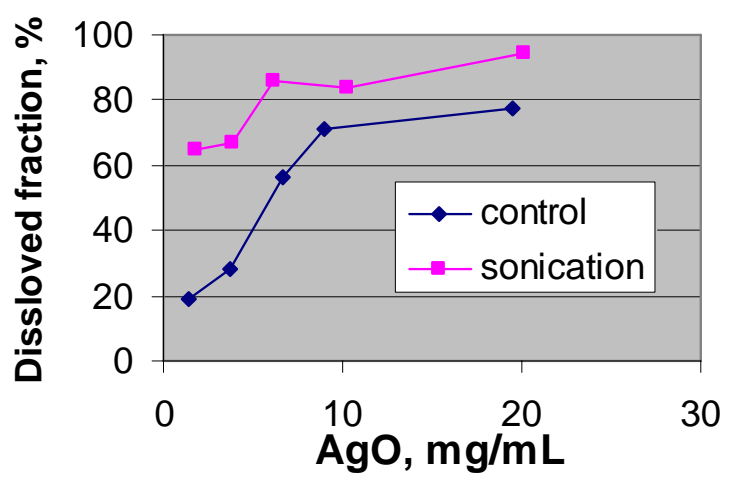

Figure 3.2. Dissolution Efficiency of $\mathrm{PuO}_{2}$ in 1.4 $\mathrm{M} \mathrm{HNO}_{3}$ in the Presence of $\mathrm{AgO}$

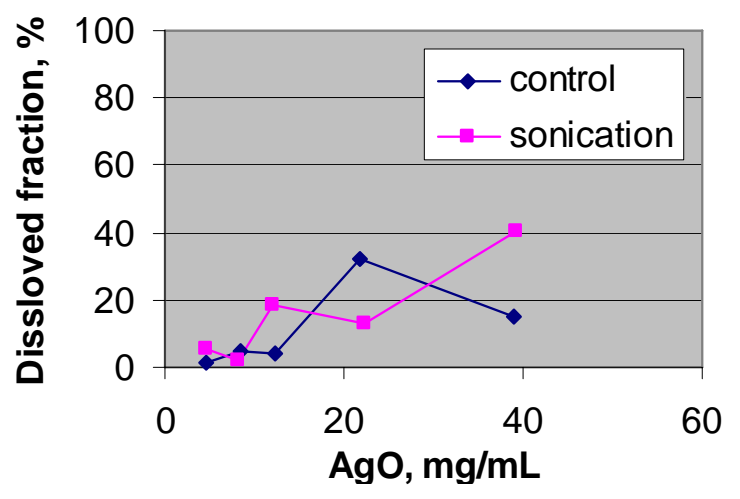

Figure 3.3. Dissolution Efficiency of $\mathrm{PuO}_{2}$ Premixed with CRS ( $29 \mu \mathrm{g}$ of $\mathrm{PuO}_{2}$ per $50 \pm 1 \mathrm{mg}$ of the CRS) in $1.4 \mathrm{M} \mathrm{HNO}_{3}$ in the Presence of $\mathrm{AgO}$ 


\section{6 $\mathrm{PuO}_{2}$ Dissolution in $\mathrm{HF}$}

Fluoride is frequently added to nitric acid to improve the dissolution of plutonium oxides. In nitric acid solution, the concentration of the free fluoride ion might be significantly suppressed by the presence of a high concentration of protons shifting the equilibrium to favor $\mathrm{HF}$ formation $\left(\mathrm{H}^{+}+\mathrm{F}^{-}=\mathrm{HF}, \mathrm{pK}_{\mathrm{a}}=3.1\right)$. Therefore, it was of interest to compare the action of fluoride in the $\mathrm{PuO}_{2}$ dissolution process as a function of free proton concentration (or more correctly, hydronium ion concentration). The lower proton concentration case was studied by applying HF alone without the presence of $\mathrm{HNO}_{3}$. Figure 3.4 presents the results of the treatment with HF. The data suggest a very minor dependence of $\mathrm{PuO}_{2}$ dissolution efficiency on the $\mathrm{HF}$ concentration under sonication, with slighter better results for higher HF concentrations. The control experiment data are very scattered, perhaps because of poor mixing during sampling or occasional penetration of a submicron fraction of unreacted $\mathrm{PuO}_{2}$ into filtrates at the filtration stage. Overall, there is no indication that sonication offers any benefits in dissolution efficiency of $\mathrm{PuO}_{2}$ compared with the conventional treatment. Complete dissolution of $\mathrm{PuO}_{2}$ was not achieved in the $\mathrm{HF}$ concentration range tested, and there was no advantage in $\mathrm{HF}$ concentrations higher than $6 \mathrm{M}$ in dissolving $\mathrm{PuO}_{2}$ under sonication.

\section{7 $\mathrm{PuO}_{2}$ Dissolution in Mixtures of $\mathrm{HF}$ and $\mathrm{HNO}_{3}$}

In an attempt to improve the dissolution yield of $\mathrm{PuO}_{2}$ in $\mathrm{HF}$ solution, we performed two more series of experiments in which nitric acid was added to the HF solution. In the first series, we maintained the nitric acid concentration constant at $8 \mathrm{M}$ and varied the HF concentration from 1.4 to $7 \mathrm{M}$. Figure 3.5 presents the results of this experiment. Despite the presence of the strong acid - which suppresses the free fluoride ion concentration - the addition of $8 \mathrm{M} \mathrm{HNO}_{3}$ to $2.8 \mathrm{M} \mathrm{HF}$ resulted in an $18 \%$ improvement in the $\mathrm{PuO}_{2}$ dissolution efficiency for the samples not sonicated (i.e., the control experiments) and an $18 \%$ improvement in the sonicated samples. At 5.6 M HF, modest improvement was observed as well ( $2 \%$ and $8 \%$ for control and sonication experiments, respectively). The highest dissolution of $\mathrm{PuO}_{2}$ in the $\mathrm{HF}+\mathrm{HNO}_{3}$ series was $98 \%$, which was observed for 4.2 M HF/8 $\mathrm{M} \mathrm{HNO}_{3}$ with sonication. The control series curve also exhibits maximum dissolution at this concentration of HF (94\%). The dissolution efficiency decreases by ca. $8 \%$ when nitric and hydrofluoric acid concentrations become comparable to each other (see the last two pairs of data points in Figure 3.5). It appears that a sufficiently strong concentration of free protons supplied by nitric acid is needed in addition to the presence of substantial concentrations of the fluoride containing species $\left(\mathrm{HF}+\mathrm{F}^{-}\right)$to achieve dissolution yields of $\mathrm{PuO}_{2}$ higher than $95 \%$. In addition to contributing high acidity, nitric acid also

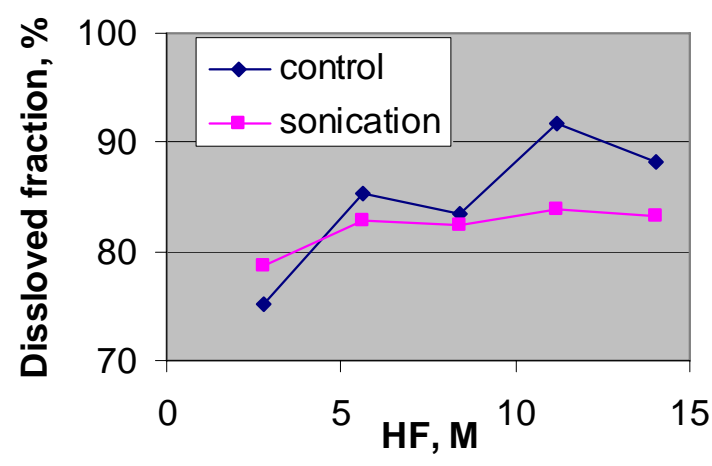

Figure 3.4. Dissolution Efficiency of $\mathrm{PuO}_{2}$ in Hydrofluoric Acid

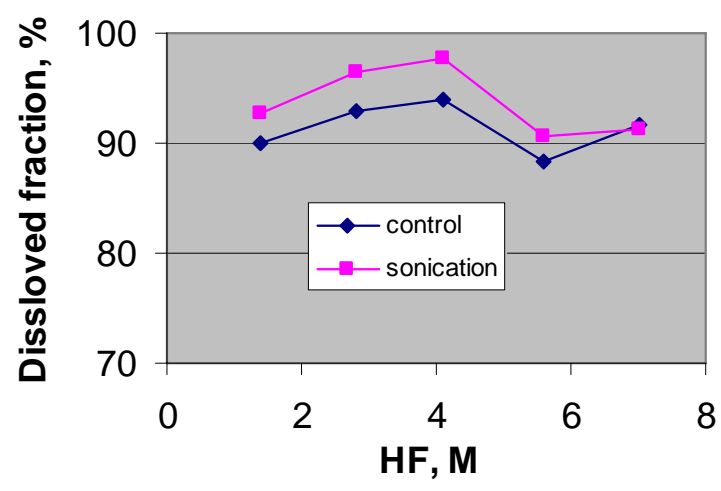

Figure 3.5. Dissolution Efficiency of $\mathrm{PuO}_{2}$ in $\mathrm{HF}$ Solution in $8 \mathrm{M} \mathrm{HNO}_{3}$ 
serves as a nitrate-supplying agent that might participate in the formation of mixed fluoro-nitrato complexes of $\mathrm{Pu}(\mathrm{IV})$.

The second series of $\mathrm{HF} / \mathrm{HNO}_{3}$ experiments was performed at a constant $\mathrm{HF}$ concentration of $14 \mathrm{M}$ with the $\mathrm{HNO}_{3}$ concentration varied from $0.4 \mathrm{M}$ to $8 \mathrm{M}$. Figure 3.6 shows the results of this experiment. In this case, a low $\mathrm{HNO}_{3}$ concentration in the sonication series results in a minor suppression of the dissolution yield of $\mathrm{PuO}_{2}\left(75 \%\right.$ and $81 \%$ at $0.4 \mathrm{M}$ and $2.0 \mathrm{M} \mathrm{HNO}_{3}$, respectively, versus $83 \%$ observed in the absence of $\mathrm{HNO}_{3}$ [Figure 3.4]). But increasing $\left[\mathrm{HNO}_{3}\right]$ further promotes the additional dissolution of $\mathrm{PuO}_{2}$, and starting from $6 \mathrm{M} \mathrm{HNO}_{3}$, the dissolution yield approaches $95 \%$. It appears that both the $4: 8=1: 2$ and 14:7 = 2:1 molar concentration ratios of $\mathrm{HF}$ to $\mathrm{HNO}_{3}$ are equally effective in terms of achieving practically quantitative dissolution of plutonium dioxide in the double mixture of these acids. Contrary to the previous series of experiments, all control samples show a very minor but systematically higher dissolution efficiency than the sonicated samples. The $130 \%$ dissolution efficiency measured for the last control sample is obviously an artifact most likely related to insufficient mixing of the sample during sampling

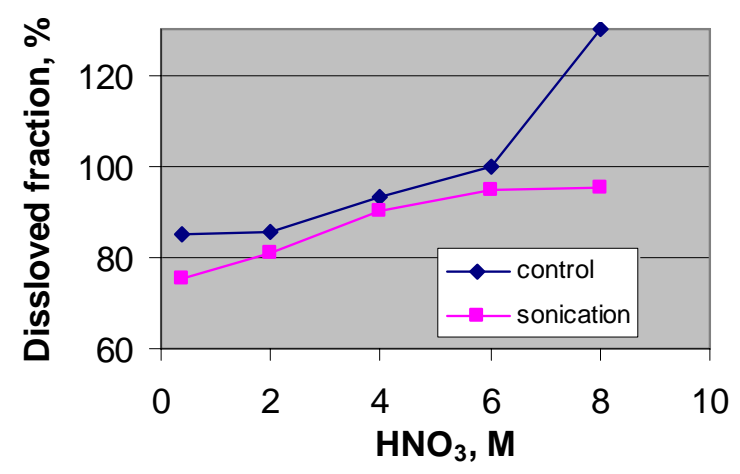

Figure 3.6. Dissolution Efficiency of $\mathrm{PuO}_{2}$ in $\mathrm{HNO}_{3}$ Solution in $14 \mathrm{M} \mathrm{HF}$ 


\subsection{Conclusions and Recommendations}

The major findings of this work can be summarized as follows:

- High-fired $\mathrm{PuO}_{2}$ does not undergo measurable dissolution when sonicated in nitric acid solutions, even at a high concentration range of $\mathrm{HNO}_{3}$ where the calculated thermodynamic solubility of $\mathrm{PuO}_{2}$ exceeds the $\mu \mathrm{g} / \mathrm{mL}$ level (Ryan and Bray 1980).

- The application of certain organic complexants (NTA) and reductants (HU) in $1.5 \mathrm{M} \mathrm{HNO}_{3}$ does not significantly increase the dissolution compared with digestion in nitric acid alone. Nearly all (99.5\%) of the $\mathrm{PuO}_{2}$ remains undissolved under these conditions.

- The action of a strong inorganic reductant, $\mathrm{TiCl}_{3}$ in $25 \% \mathrm{HCl}$, results in $40 \%$ dissolution of the $\mathrm{PuO}_{2}$ when the $\mathrm{TiCl}_{3}$ concentration is $\geq 1 \%$ under sonication.

- The oxidative treatment of $\mathrm{PuO}_{2}$ by freshly dissolved $\mathrm{AgO}(\sim 20 \mathrm{mg} / \mathrm{mL})$ in $1.5 \mathrm{M} \mathrm{HNO}_{3}$ resulted in $95 \% \mathrm{PuO}_{2}$ dissolution. However, the same treatment of $\mathrm{PuO}_{2}$ mechanically mixed with $50 \mathrm{mg}$ of CRS results in a significant decrease of dissolution yield of $\mathrm{PuO}_{2}(<20 \%$ dissolved at the same $\mathrm{AgO}$ loading), likely because of parasitic consumption of $\mathrm{Ag}^{2+}$ by oxidizable components of the CRS.

- The digestion of $\mathrm{PuO}_{2}$ in $\mathrm{HF}$ resulted in dissolution yields slightly higher than $80 \%$ for $\mathrm{HF}$ concentration from $6 \mathrm{M}$ to $14 \mathrm{M}$. Sonication did not result in any improvement in dissolution efficiency in HF.

- Mixed nitric acid/HF solutions result in a higher dissolution yield of $\mathrm{PuO}_{2}$ compared with digestion in $\mathrm{HF}$ alone (at the same HF concentrations). Practically quantitative dissolution of $\mathrm{PuO}_{2}$ can be achieved with 6 to $8 \mathrm{M} \mathrm{HNO}_{3}+14 \mathrm{M} \mathrm{HF}$ or $8 \mathrm{M} \mathrm{HNO}_{3}+4 \mathrm{M} \mathrm{HF}$ mixtures. In the latter case, quantitative dissolution of $\mathrm{PuO}_{2}$ was demonstrated only with sonication.

Overall, the results indicate that applying ultrasound in an isolated cup horn configuration for the dissolution of refractory $\mathrm{PuO}_{2}$ does not offer any substantial advantage over the conventional "heat and mix" treatment. Oxidative treatment by AgO appears to be effective only when very little or no oxidizable materials are present in the digested sample. The catalytic use of $\mathrm{Ag}^{2+}$ in the CEPOD technology would probably be more effective than using $\mathrm{AgO}$ because the $\mathrm{Ag}^{2+}$ is continually regenerated electrochemically. Reductive treatment with $\mathrm{TiCl}_{3}$ in an $\mathrm{HCl}$ medium proves to be less efficient than the previously explored effect based on in situ generation of $\mathrm{Ti}^{3+}$ in $\mathrm{H}_{3} \mathrm{PO}_{4}$ and $\mathrm{H}_{2} \mathrm{SO}_{4}$ media using a dip probe sonication geometry. The previous experiments, however, were performed at higher temperature and with non-steady concentration profiles of $\mathrm{Ti}^{3+}$ in the process of sonochemical digestion. 


\subsection{References}

Banwart S, S Davies, and W Stumm. 1989. "The Role of Oxalate in Accelerating the Reductive Dissolution of Hematite $\left(\alpha-\mathrm{Fe}_{2} \mathrm{O}_{3}\right)$ by Ascorbate." Colloids Surf. 39:303-309.

National Institute for Standards and Technology (NIST). 1981. National Bureau of Standards Certificate for Standard Reference Material. Source ID 4350B (River Sediment).

Ryan JL., and LA Bray. 1980. "Dissolution of Plutonium Dioxide - A Critical Review." In: Actinides Separations. Navratil JD, and WW Schulz (Eds.), ACS Symposium Series 117, 499-514.

Ryan JL., LA Bray, EJ Wheelwright, and GH Bryan. 1992. "Catalyzed Electrolytic Plutonium Oxide Dissolution.” Chapter 30. In: Transuranium Elements: A Half Century, LR Morss and J Fuger, Eds. ACS Books, Washington, DC, 288-304.

Sinkov SI, and GJ Lumetta. 2006. "Application of Liquid Waveguide Capillary Cell Based Optical Absorbance Spectroscopy for Enhanced Actinide Speciation and Complexation." In: Abstracts of the $30^{\text {th }}$ Actinides Separation Conference. May 23-25, 2006, p. 29.

Suslick KS (Ed.). 1988. Ultrasound, its Chemical, Physical and Biological Effect. VCH Press, New York, NY.

Zhaowu Z, H Jianyu, Z Zefu, Z Yu, and Z Weifang. 2004. "Kinetics of the Reduction of Plutonium(IV) by Hydroxyurea, a Novel Salt-Free Agent." Journal of Radioanalytical and Nuclear Chemistry. 260(4):601-606. 
PNNL-16035

\section{Distribution}

No. of

Copies

OFFSITE

2 U.S. Department of Energy National Nuclear Security Agency (DOE/NA-22)

Les Pitts

NNSA/NA-22, GH-068

U.S. Department of Energy (Forrestal Bldg.) 1000 Independence Avenue, S.W.

Washington, D.C. 20585

Alan Icenhour

NNSA/NA-22, GH-068

U.S. Department of Energy (Forrestal Bldg.) 1000 Independence Avenue, S.W.

Washington, D.C. 20585

1 Los Alamos National Laboratory

Pat Brug

Los Alamos National Laboratory

P.O. Box 1663

Los Alamos, NM 87545
No. of

Copies

ONSITE

12 Pacific Northwest National Laboratory

S. Bonde

P8-50

R. G. Clemmer

K8-02

D. A. Dickman

K8-46

G. B. Dudder

K8-02

J. I. Friese

$\mathrm{P} 8-01$

J. W. Grate

K8-93

G. J. Lumetta

P7-22

T. C. Maiti

P7-07

M. J. O'Hara

P7-22

S. L. Petersen

P7-07

S. W. Sharpe

K8-02

J. F. Wacker

P7-07

Distr. 1 